\title{
O conversar como estratégia de formação contínua na tutoria da educação profissional a distância
}

\author{
FERNANDO AUGUSTO TREPTOW BROD \\ Instituto Federal Sul-Rio-Grandense, Pelotas, RS, Brasil \\ SHEYLA COSTA RODRIGUES \\ Universidade Federal do Rio Grande, Rio Grande, RS, Brasil
}

\section{RESUMO}

Este estudo propõe uma reflexão valendo-se do conversar dos professores tutores da educação profissional a distância da Rede e-Tec do Instituto Federal de Educação, Ciência e Tecnologia Sul-rio-grandense, campus Visconde da Graça (IFSul CAVG) sobre o trabalho de mediação pedagógica que realizam na tutoria. Trouxemos, desse conversar, os temas que foram recursivos e os analisamos por meio da técnica do discurso do sujeito coletivo de Lefèvre e Lefêvre. $\mathrm{Na}$ análise, sustentamos as interlocuções com os autores Maturana, Lévy, Shulman e Tardif por meio dos conceitos: cultura em redes de conversação, inteligência coletiva, conhecimento pedagógico do conteúdo e formação profissional docente. Os discursos coletivos assinalam para os reflexos ocasionados pela falta de interação entre os professores pesquisadores e os professores tutores e seus impactos no processo de mediação pedagógica.

PALAVRAS-CHAVE

educação profissional a distância; tutoria; mediação pedagógica. 


\title{
THE CONVERSATION AS A STRATEGY FOR CONTINUED FORMATION IN THE TUTORSHIP OF PROFESSIONAL DISTANCE EDUCATION
}

\begin{abstract}
This study proposes to reflect about the conversations of professors/tutors of vocational distance education of Rede e-Tec Instituto Federal de Educação, Ciência e Tecnologia Sul-rio-grandense, campus Visconde da Graça (IFSul CAVG), considering the pedagogical mediation work performed by them in the tutoring. We brought the conversation's recursive topics to the study and analyzed it using the technique of the collective subject discourse of Lefèvre and Lefèvre. In our analysis, we use the theoretical background of the scholars Maturana, Lévy, Shulman and Tardif, through the following concepts: culture in conversation networks, collective intelligence, pedagogical knowledge content, and teacher training. The collective discourse indicates the consequences caused by the lack of interaction between professors/researchers and professors/tutors and its impact on the pedagogical mediation.
\end{abstract}

KEYWORDS

distance professional education; tutoring; pedagogical mediation.

\section{EL ACTO DE CONVERSAR COMO ESTRATEGIA DE FORMACIÓN CONTINUADA EN LA TUTORÍA DE EDUCACIÓN PROFESIONAL A DISTANCIA}

\section{RESUMEN}

Este estudio propone una reflexión, valiéndose de la práctica de conversar de los profesores tutores de la formación profesional a distancia de la red e-Tec del Instituto Federal de Educação, Ciência e Tecnologia Sul-riograndense, campus Visconde da Graça (IFSul CAVG) sobre el trabajo de mediación pedagógica que llevan a cabo en la tutoría. Trajimos de esa práctica de conversar, los temas recursivos, y los analizamos por medio de la técnica del discurso del sujeto colectivo de Lefèvre y Lefèvre. En el análisis, mantuvimos interlocuciones con los autores Maturana, Lévy, Shulman y Tardif, por medio de los conceptos: cultura en redes de conversación, inteligencia colectiva, conocimiento pedagógico del contenido, y formación profesional docente. Los discursos colectivos señalan las consecuencias de la falta de interacción entre los profesores investigadores y los profesores tutores y su impacto en el proceso de mediación pedagógica.

PALABRAS CLAVE

educación profesional a distancia; tutoría; mediación pedagógica. 


\section{INTRODUÇÃO}

Segundo dados ${ }^{1}$ da Secretaria de Assuntos Estratégicos da Presidência da República (SAE/PR), o Brasil vive uma intensa fase de imigração estrangeira em virtude da falta de mão de obra qualificada para atender às empresas. Uma alternativa para democratizar a "educação para o trabalho" e atenuar esse quadro encontra-se em desenvolvimento pela Rede e-Tec Brasil. ${ }^{2}$ A rede contribui para o aumento da oferta de vagas da educação profissional e oportuniza o acesso aos que se encontram distanciados de instituições de ensino técnico e tecnológico, quer geograficamente, quer por motivos de mobilidade para permanecer nos espaços institucionais de educação profissionalizante em datas e horários determinados. Trata-se de um modelo de educação profissional de nível médio permeado pelas tecnologias digitais, com apoio presencial em polos municipais e a distância, realizado por meio de ambientes virtuais de aprendizagem (AVA).

Com a expansão da rede federal de educação profissional, o Ministério da Educação (MEC) lançou, em 2007, o programa Escola Técnica Aberta do Brasil (e-Tec), com a finalidade de ampliar a oferta e democratizar o acesso a cursos técnicos de nível médio, públicos e gratuitos no país. Os cursos são desenvolvidos e ministrados na modalidade a distância, em regime de colaboração entre instituições públicas federais, estaduais e municipais.

Ao fazer parte da Rede e-Tec, o Instituto Federal de Educação, Ciência e Tecnologia Sul-rio-grandense, campus Visconde da Graça (IFSul CAVG), ${ }^{3}$ assumiu o desafio de ampliar seu programa de ensino profissionalizante em uma nova perspectiva educacional, na qual os conteúdos curriculares são preparados para serem mediados pedagogicamente por professores tutores por meio das tecnologias de comunicação disponíveis na internet.

A Rede e-Tec tem como premissa a aplicabilidade de conhecimentos técnicos no mundo do trabalho, como o estudo do leite e seus derivados em um curso técnico em agroindústria. ${ }^{4}$ Aspectos relacionados à obtenção e industrialização do leite - desde a síntese no animal até a industrialização do produto para a obtenção do leite pasteurizado e esterilizado - e às tecnologias utilizadas para o processamento do queijo, iogurte, doce de leite e manteiga são exemplos de conhecimentos teóricos, práticos e científicos de aplicabilidade no mundo do trabalho que podem transformar o fazer das pessoas pelo simples fato de serem trabalhados conteúdos que fazem parte do cotidiano.

Os cursos têm duração de dois anos; as disciplinas (em média vinte por curso) são de responsabilidade de professores pesquisadores, geralmente vinculados

1 Disponível em: <http://www.sae.gov.br/site/?p=14995>. Acesso em: 22 jul. 2013.

2 Disponível em: <http://redeetec.mec.gov.br>. Acesso em: 22 jul. 2013.

3 O IFSul CAVG é um dos campi integrante do Instituto Federal de Educação, Ciência e Tecnologia Sul-rio-grandense, denominando-se IFSul campus Pelotas - Visconde da Graça.

4 Disponível em: <http://www.ifsul.edu.br/proen/site/catalogo_curso.php?cod=75>. Acesso em: 28 ago. 2013. 
ao quadro docente dos institutos federais de educação, ciência e tecnologia, e de professores tutores presenciais e a distância, que em sua maioria fazem parte das redes federal, estadual e municipal, contratados para mediar o seu desenvolvimento. Os professores tutores são selecionados por edital público pelo período de dois anos para atuarem presencialmente nos polos de cada município, e a distância na tutoria do polo gestor, por meio de um AVA, ambos como mediadores no processo de ensino e aprendizagem.

No modelo de educação proposto pela Rede e-Tec, o professor tutor é contratado para interagir com os alunos em todas as disciplinas do curso. Se, por um lado, isso the permite conhecer a realidade de seus alunos e, assim, estabelecer experiências afetivas e colaborativas durante o acompanhamento de seus estudos, por outro lado the exige um esforço pedagógico de apropriação e mediação dos conteúdos específicos nas diversas disciplinas que integram os currículos de cada curso técnico.

Neste trabalho, o ponto central da discussão é fazer uma reflexão sobre o conversar dos professores tutores no processo de mediação pedagógica desenvolvido a distância nos cursos de administração, agroindústria, biocombustíveis e contabilidade da Rede e-Tec do IFSul CAVG, ${ }^{5}$ nos anos de 2012 e 2013. Para tanto, problematizamos como os professores tutores apropriam-se dos conhecimentos específicos em cada uma das disciplinas dos cursos técnicos para mediá-las pedagogicamente com os alunos.

\section{TUTORIA E MEDIAÇÃO PEDAGÓGICA NA EDUCAÇÃO PROFISSIONAL A DISTÂNCIA}

Para compreender a educação a distância $(\mathrm{EaD})$ na perspectiva da democratização do ensino profissionalizante, encontramos nas ideias de Humberto Maturana (1999) a possibilidade de ampliar o espaço de conversações, rompendo com as barreiras culturais, econômicas e sociais para democratizar o viver em encontros reflexivos sobre os diversos temas que a educação a distância pode oferecer. Para o autor, a educação a distância oferece conhecimento de maneira distribuída, permitindo o encontro entre pessoas de qualquer origem em projetos comuns; respeita o ritmo de aprendizagem de cada estudante; além de operar em dinâmicas que aceitam qualquer pergunta como válida, por meio de atendimento tutorial, pessoal e não valorativo $(i d e m)$.

Segundo Moore e Kearsley (2008), a EaD evoluiu ao longo da história, iniciando por meio de cursos de instrução por correspondência e avançando com as tecnologias de comunicação, como telefone, rádio, televisão, satélite, cabos e redes de computadores. A geração mais recente caracteriza-se por cursos a distância apoiados por AVA, ${ }^{6}$ baseados em tecnologias de comunicação da internet.

5 Disponível em: <http://cavg.ifsul.edu.br/ead.html>. Acesso em: 28 ago. 2013.

6 AVA: conjuntos de ferramentas e recursos tecnológicos utilizados para gerenciar conteúdos em cursos a distância e permitir a interação virtual entre professores e alunos 
De acordo com Lévy (1998, p. 29), essas novas possibilidades de comunicação por meio do ciberespaço ${ }^{7}$ têm motivado "interações entre conhecimentos e conhecedores de coletivos inteligentes desterritorializados". Para o autor, jamais a evolução das ciências e das técnicas foi tão veloz, com tantas consequências sobre a vida cotidiana, democratizando a liberdade de expressão, em especial na mídia digital. Na perspectiva da $\mathrm{EaD}$, o autor faz referências aos saberes desterritorializados que, construídos colaborativamente com as ferramentas de comunicação digital, propiciam condições profícuas para a composição da inteligência coletiva.

A inteligência coletiva é definida pelo autor como "uma inteligência distribuída por toda parte, incessantemente valorizada, coordenada em tempo real, que resulta em uma mobilização efetiva das competências" (idem, p. 28). Seu objetivo, conforme Lévy (idem, p. 29), é "o reconhecimento e o enriquecimento mútuos das pessoas". Compreendemos, assim, a $\mathrm{EaD}$, apoiada pelo ciberespaço, como uma inteligência coletiva que possibilita a produção de conhecimentos por meio de interações coletivas e desterritorializadas, desenvolvidas de forma colaborativa e descentralizada em rede.

Sistemas de tutoria têm sido organizados para interagir colaborativamente com os alunos nesse modelo educativo, cabendo aos professores tutores a distância a mediação pedagógica nos cursos por meio da rede. No cenário da $\mathrm{EaD}$, a tutoria tem o papel de atenuar o distanciamento entre os extremos do sistema instituição-aluno. Gonzalez (2005, p. 21) indica que a palavra "tutor" não pode ser utilizada de forma indiscriminada, havendo a necessidade de um movimento de ressignificação para superar a ideia do tutor "como aquele que ampara, protege, defende, dirige ou que tutela alguém". Além disso, o autor ressalta que o papel do tutor extrapola os limites conceituais impostos na nomenclatura, já que, em sua missão essencial, trata-se de um educador como os demais sujeitos envolvidos no processo de ensino e de aprendizagem.

Nos cursos profissionais a distância apoiados pelas tecnologias digitais, o tutor é o professor que interage com o aluno por meio do ambiente virtual, buscando mediar as aprendizagens de uma maneira particular e, portanto, "estar disposto a reconhecer o que não sabe e a buscar respostas para perguntas que o surpreendem" (Maturana, 1999, p. 151, tradução nossa). De acordo com o autor, o professor tutor deve, por um lado, realizar a mediação para que o aluno adquira suas habilidades operacionais nos temas que se propõe a estudar, e, por outro, guiar o emocionar desse aluno para uma liberdade reflexiva, relativa ou não ao tema.

$\mathrm{Na}$ resolução CD/FNDE n. 18, de 16 de junho de 2010, ${ }^{8}$ encontramos algumas atribuições do professor tutor do Programa e-Tec Brasil: assistir os alunos

no processo educativo por meio das tecnologias de comunicação da internet (Pereira, 2007).

7 Ciberespaço: meio de comunicação que surge da interconexão mundial de computadores (Lévy, 1999, p. 16-17).

8 Disponível em: <http:/www.fnde.gov.br/fnde/legislacao/resolucoes/item/3400-resolu\%C3\%A7\%C3\%A3o-cd-fnde-n\%C2\%BA-18-de-16-de-junho-de-2010>. Acesso em: 19 jun. 2013. 
nas atividades do curso; mediar a comunicação de conteúdos entre o professor e os cursistas; estabelecer e promover contato permanente com os alunos. Pela resolução, percebemos que o modelo de $\mathrm{EaD}$ da Rede e-Tec atribui ao professor tutor a função de mediar os conteúdos curriculares entre o professor pesquisador e os alunos, ficando a cargo do professor pesquisador a preparação e a organização da disciplina no ambiente, o planejamento, o desenvolvimento e a avaliação de metodologias de ensino dos cursos e o acompanhamento das atividades de ensino.

Segundo Gutierrez e Prieto (1994, p. 62), é importante diferenciar um modelo pedagógico, que tem por objetivo educar, de um modelo temático conteudista, que tem como propósito ensinar ou transmitir conhecimento, porque "a mediação pedagógica parte de uma concepção radicalmente oposta aos sistemas de instrução baseados na primazia do ensino como mera transferência de informação".

Para Masetto (2012, p. 145), a mediação pedagógica compreende:

dialogar permanentemente de acordo com o que acontece no momento; trocar experiências; debater dúvidas, questões ou problemas; apresentar perguntas orientadoras; orientar nas carências e dificuldades técnicas ou de conhecimento quando o aprendiz não consegue encaminhá-las sozinho; garantir a dinâmica do processo de aprendizagem; propor situações-problema e desafios; desencadear e incentivar reflexões; criar intercâmbio entre a aprendizagem e a sociedade real onde nos encontramos, nos mais diferentes aspectos; colaborar para estabelecer conexões entre o conhecimento adquirido e novos conceitos; fazer a ponte com outras situações análogas; colocar o aprendiz frente a frente com questões éticas, sociais, profissionais por vezes conflitivas; colaborar para desenvolver crítica com relação à quantidade e à validade das informações obtidas; cooperar para que o aprendiz use e comande as novas tecnologias para suas aprendizagens e não seja comandado por elas ou por quem as tenha programado; colaborar para que se aprenda a comunicar conhecimentos, seja por meio de meios convencionais, seja por meio de novas tecnologias.

Lévy (1999) aponta, nesse mesmo sentido, que a competência dos professores responsáveis pela mediação pedagógica nas escolas e universidades, em ambientes virtuais, deve deslocar-se da difusão dos conhecimentos para o estímulo à aprendizagem e ao pensamento.

Motivados por essas concepções, compreendemos que a mediação pedagógica na $\mathrm{EaD}$ potencializa-se quando realizada em uma relação de interação entre os sujeitos que dela participam, na qual os conteúdos são facilitados, problematizados, (re)significados e (re)construídos; também a colaboração é favorecida quando essa rede de conversação, estabelecida entre mediador e aprendizes, é fundada no afeto, no respeito, na ética, em um domínio de aceitação mútua que legitime a convivência.

No e-Tec do IFSul CAVG, a tutoria é organizada para que os professores tutores realizem coletivamente a mediação pedagógica com os alunos, utilizando-se, para tal ação, das tecnologias de comunicação configuradas e disponíveis no ambiente. Dessa forma, consideramos relevante que os dados da pesquisa fossem coletados em uma rede de conversação estabelecida nesse espaço, no qual esses sujeitos en- 
contram-se inseridos. Encontramos no conversar ${ }^{9}$ de Maturana (2001) uma alternativa para conhecer as experiências de mediação pedagógica vividas na tutoria pelos professores tutores.

\section{O CONVERSAR E O DISCURSO DO SUJEITO COLETIVO COMO ESTRATÉGIAS DE ANÁLISE}

Convidamos para conversar sobre a mediação pedagógica na $\mathrm{EaD}$ profissional os dezesseis professores tutores a distância da Rede e-Tec do IFSul CAVG, o secretário de apoio administrativo dos cursos técnicos e a coordenadora de tutoria. As conversas realizaram-se no ambiente presencial de convívio dos professores tutores a distância em três momentos distintos, procurando contemplar os turnos em que esses professores compareciam ao ambiente para o desempenho de suas atribuições. Os atuais professores tutores a distância da Rede e-Tec do IFSul CAVG exercem a carreira de magistério na rede de ensino público federal, estadual ou municipal em concomitância com a EaD. Logo, por motivos de indisponibilidade de data e/ou horário escolhidos para a realização dos encontros, quatro professores tutores não puderam estar presentes.

O conversar partiu de assuntos relacionados ao fazer dos professores tutores, os quais tiveram liberdade para expressar e produzir livremente suas ideias. Norteamos o conversar por meio de temas relativos à apropriação dos conteúdos técnicos e específicos em cada disciplina, à mediação para transformar informações técnicas em conhecimentos, à mediação quando os conteúdos curriculares não eram de seu domínio, às práticas atreladas às tecnologias digitais que poderiam ampliar os conhecimentos pedagógico e específico dos conteúdos nas diferentes disciplinas, à relação do professor tutor com o professor pesquisador e à formação esperada para trabalhar na EaD. Foi significativa também a participação da coordenadora de tutoria e do secretário dos cursos na rede de conversação, pois estes atuam na gestão administrativa e pedagógica da rede.

As conversas foram gravadas com o consentimento prévio de todos os sujeitos envolvidos, tendo-se, como resultado, aproximadamente quatro horas de áudio para posterior análise. O material foi digitalizado por meio do software de reconhecimento de voz IBM-ViaVoice, respeitando-se, assim, sua exatidão no processo de transcrição.

O discurso do sujeito coletivo foi a estratégia metodológica adotada para analisar o conversar dos professores tutores sobre a mediação pedagógica realizada no e-Tec. O sujeito coletivo expressa-se por meio de um discurso emitido na primeira pessoa do singular, o qual representa o pensamento de uma coletividade por meio de depoimentos de diferentes indivíduos com conteúdos discursivos de sentido semelhante (Lefèvre; Lefèvre, 2005).

A técnica do discurso do sujeito coletivo desenvolvida por Lefêvre e Lefêvre (idem) aponta a entrevista como o método mais frequentemente utilizado para a

9 A palavra conversar vem da união de duas raízes latinas: cum, que significa "com", e versare, que significa "dar voltas com" o outro (Maturana, 1999, p. 167). 
coleta de dados de uma pesquisa. Entretanto, os autores ressaltam cuidados a serem tomados na elaboração das perguntas para que as respostas dos entrevistados sejam as mais espontâneas ou menos dirigidas possível. Como nossa intenção não era fazer perguntas diretivas aos professores tutores, foi necessário encontrar um método que, ao mesmo tempo, atendesse o coletivo e permitisse o livre fluxo de ideias. Encontramos no conversar de Humberto Maturana uma estratégia para observar as dinâmicas emocionais recorrentes que se originavam como resultado do entrecruzamento das diferentes conversações estabelecidas com os professores tutores.

Para o autor, construímos nossa realidade com o outro por meio do conversar, no entrelaçamento do linguajar e do emocionar, no qual "falar tem a ver constitutivamente com o agir" (Maturana, 2009, p. 77). Ainda de acordo com o autor, "emoções não são conversações, mas nós fluímos em nosso emocionar através do fluir de nossas conversações; e vice-versa, nós fluímos em nossas conversações enquanto fluímos em nosso emocionar" (Maturana, 2002, p. 284). Durante o conversar em nossa pesquisa, o emocionar de um professor tutor afetava o emocionar de outro, provocando recursividade nos discursos singulares que deram origem aos discursos coletivos.

Seguindo a técnica do discurso do sujeito coletivo, criamos uma tabela denominada instrumento de análise, conforme recorte demonstrado no Quadro 1, na qual organizamos cada um dos depoimentos nas células de uma primeira coluna, denominada "expressões-chave".

As conversas tiveram trechos realçados para sintetizar a sua essência. Cada conjunto de expressões-chave originou uma célula adjacente, que procurou registrar de maneira legítima os sentidos de cada um dos discursos analisados. A segunda coluna recebeu a denominação de "ideias centrais". Na terceira coluna da tabela, procuramos anotar as "ancoragens", denominação proposta pela técnica do discurso do sujeito coletivo para as marcas linguísticas, às vezes presentes nos discursos, que se mostram alicerçadas em pressupostos ou conceitos teóricos. Na quarta coluna categorizamos as ideias centrais, associando-as a uma letra (A, B, C), que, após a classificação, agrupou os pensamentos de sentido equivalente, fazendo emergir os discursos coletivos.

Do resultado da análise emergiram quatro discursos coletivos: "Normatizar como estratégia para profissionalizar a tutoria"; "Conhecimentos conceitual e pedagógico dos conteúdos"; "Interação técnico-pedagógica"; e "Cultura e formação na EaD”. A seguir discutimos cada um dos quatro discursos coletivos, problematizando-os com apoio teórico para sustentar nossas reflexões.

\section{A PROFISSIONALIZAÇÃO DA TUTORIA NA EDUCAÇÃO PROFISSIONAL A DISTÂNCIA}

O primeiro discurso coletivo (DSC1) emergiu do agrupamento das expressões-chave cujo sentido distinguiu, como ideias centrais, o trabalho burocrático realizado pelo professor tutor, a necessidade de uma normatização para regulamentar as questões pedagógicas na tutoria e a profissionalização da função tutor. 
Quadro 1 - Instrumento de análise

\begin{tabular}{|c|c|c|c|}
\hline Expressões-chave & Ideias centrais & Ancoragem & Categoria \\
\hline $\begin{array}{l}\text { Quando eu entrei aqui, eu pensei: "vou } \\
\text { aprender..." Eu estou procurando aprender } \\
\text { até agora, porque não tive esse intercâmbio, } \\
\text { porque o meu afazer como tutor é corrigir } \\
\text { prova, corrigir trabalhos, não é mediar } \\
\text { conteúdo do aluno, porque mediar conteúdo } \\
\text { do aluno ficou bem claro que seria do } \\
\text { professor. Quando o professor está presente } \\
\text { no ambiente, porque tem professor que nem } \\
\text { entra no ambiente... }\end{array}$ & $\begin{array}{l}- \text { Trabalho } \\
\text { burocrático }\end{array}$ & & A \\
\hline $\begin{array}{l}\text { Eu acredito muito nesta questão pedagógica, } \\
\text { nós poderíamos ser muito melhor utilizados } \\
\text { pelo programa do que nós estamos sendo, } \\
\text { nosso trabalho é burocrático, a gente cumpre } \\
\text { hora. Por exemplo, a gente só corrige, só } \\
\text { intervém numa avaliação se o professor } \\
\text { mandar o gabarito, aquelas objetivas. As } \\
\text { questões discursivas aí são com o professor. }\end{array}$ & $\begin{array}{l}\text { - Trabalho } \\
\text { burocrático } \\
\text { - Normatização } \\
\text { - Domínio de } \\
\text { conteúdo }\end{array}$ & $\begin{array}{l}\text { - Conhecimento } \\
\text { pedagógico } \\
\text { do conteúdo }\end{array}$ & ADI \\
\hline $\begin{array}{l}\text { Se a gente se fortalecer enquanto instituição, } \\
\text { nesse vínculo, coordenação, professor, tutor, } \\
\text { a gente vai chegar lá no aluno muito melhor. } \\
\text { Essa coisa é uma ponta, tutor-professor é } \\
\text { uma ponta, mas a gente tem que trabalhar } \\
\text { coisas anteriores. }\end{array}$ & - Interação & $\begin{array}{l}\text { - Transformação } \\
\text { na convivência }\end{array}$ & $\mathrm{B}$ \\
\hline $\begin{array}{l}\text { Eu acho que deveria ter uma normatização } \\
\text { dos professores com os tutores, nós não } \\
\text { sabemos o nosso papel. }\end{array}$ & - Profissionalização & $\begin{array}{l}\cdot \text { Formação } \\
\text { profissional }\end{array}$ & $\mathrm{H}$ \\
\hline $\begin{array}{l}\text { Se o professor não te dá o apoio, também é } \\
\text { anti-humano o tutor conseguir responder aos } \\
\text { alunos }\end{array}$ & • Mediação & & $\mathrm{C}$ \\
\hline $\begin{array}{l}\text { O comprometimento que o professor tem } \\
\text { no presencial tem que ter no a distância. } \\
\text { Quantas vezes você anda atrás, manda } \\
\text { mensagem para o professor para dar uma } \\
\text { determinada resposta? Tem momentos } \\
\text { que o professor não responde, como tem } \\
\text { momentos que o professor não fala como } \\
\text { aluno. Tem que começar um trabalho } \\
\text { de conscientização com o professor. }\end{array}$ & $\begin{array}{l}\text { - Cultura } \\
\text { - Profissionalização }\end{array}$ & $\begin{array}{l}\text { - Os fins do } \\
\text { trabalho } \\
\text { docente }\end{array}$ & $\mathrm{GH}$ \\
\hline
\end{tabular}

Fonte: Banco de dados da pesquisa, 2013.

Elaboração dos autores.

\section{DSC1 - Normatizar como estratégia para profissionalizar a tutoria}

Nós poderíamos ser muito melhor utilizados pelo programa do que nós estamos sendo. $\mathrm{O}$ meu afazer como tutor é corrigir prova, corrigir trabalhos, não é mediar conteúdo do aluno. Nosso trabalho é burocrático, a gente cumpre hora. Eu sei que é curso técnico, mas falta uma questão mais pedagógica, parece que ficou burocrático. $\mathrm{O}$ professor lança a disciplina, lança apostila, o aluno resolve 
os exercícios e pronto. A gente ficou como se fosse um corretor. Nunca se demarcou realmente quem tem papel de quê, até onde que pode fazer o quê. Qual é a função do tutor com relação à mediação conteudista? Eu acho que deveria ter uma normatização dos professores com os tutores, nós não sabemos o nosso papel. A gente vem pra cá e cumpre as 20 horas, mas não tem sido criado um espaço coletivo de discussão. Eu não acredito que um grupo possa se qualificar se não tiver estudo, então eu acho superimportante um horário além desse, ou junto com esse, que tivesse uma reunião por semana dos tutores com os professores, um turno de formação. Os alunos estão procurando mais o professor, muitas vezes, do que o tutor. Eu acho que, quando o curso inicia, ou a disciplina, falta orientar os alunos de que o primeiro caminho é o tutor. A função do tutor nunca foi clara. Se a gente fosse efetivamente profissional, a perspectiva seria totalmente diferente, aí tu poderias ser efetivamente cobrado. A gente não é profissional, não existe um vínculo. Não há interesse do governo em fazer esta profissionalização. Quando tu te tornas profissional, na maioria das vezes tu és um pouco mais valorizado, tu não deixas aquilo ser um bico. $\mathrm{O}$ tutor também tem que ser respeitado como professor, ele é um professor, ele é um profissional. Tem que afinar sem confundir, é a condição professor tutor.

Por meio do discurso coletivo, os professores tutores destacam que, na maior parte do tempo, não atuam efetivamente na mediação pedagógica dos conteúdos curriculares, permanecendo, no espaço da tutoria, em um fazer burocrático. Pelo discurso, deixam antever que os professores pesquisadores não têm valorizado seus conhecimentos e habilidades profissionais para o desempenho das atividades pedagógicas relacionadas aos conteúdos. Sugerem uma normatização que regulamente essa relação colaborativa entre eles e os professores pesquisadores; caso contrário, segundo o discurso coletivo, correm o risco de não desempenharem mais a função pedagógica de mediação com os alunos.

A crise de identidade por que passam esses professores tutores ressalta o desejo de profissionalizar a função "tutor" ${ }^{10}$ Talvez a própria resolução n. 18 pudesse ser considerada um marco para regulamentar a função, visto que esta define algumas de suas atribuições; entretanto, não resolve as questões pedagógicas, havendo ainda a necessidade de aprofundar discussões quanto às práticas de ensino realizadas entre professores pesquisadores e professores tutores, para atingir seus objetivos no âmbito da mediação pedagógica com os alunos.

Observamos a normatização ressaltada no discurso coletivo como um passo importante para o caminho da profissionalização da função "tutor", pois busca assegurar um espaço de construção coletivo e colaborativo entre professores pesquisadores e professores tutores para discussão e experimentação das questões de domínio conceitual e específico em cada curso. $\mathrm{Na}$ convivência, os professores

10 O termo "professor tutor", em lugar de "tutor", tem a finalidade de observar o sujeito da pesquisa como mediador do processo pedagógico. 
tutores podem apropriar-se dos conteúdos curriculares, não para ensiná-los, mas para mediá-los pedagogicamente com os alunos.

A função "tutor" ainda não se encontra regulamentada como profissão. Existem entidades, como a Associação Nacional dos Tutores da Educação a Distância (ANATED), ${ }^{11}$ que representam os tutores associados em território nacional e internacional, tendo como objetivo fortalecer, organizar, incentivar e difundir o trabalho do tutor nas comunidades científicas, acadêmicas e na sociedade em geral.

No discurso coletivo, os professores tutores apontam que a tutoria tem sido desempenhada como um "bico", pois nem eles mesmos se reconhecem nesse espaço como professores de formação. O "bico" é um termo empregado para se referirem à falta de identidade e qualificação para a função. A normatização pode, portanto, ser vista como uma maneira de profissionalizar a atuação do professor tutor, já que este, muitas vezes, não tem a formação específica na área correspondente ao curso em que atua. Há que existir, assim, um espaço para sua formação contínua, que poderia ser efetivada por meio da profissionalização.

De suas conversas, pode-se inferir que uma formação contínua permitiria subsidiar os conhecimentos específicos, relativos a cada curso, aos professores tutores, pois, conforme Tardif (2012, p. 241), "se quero saber como realizar um trabalho qualquer, o procedimento mais normal consiste em aprendê-lo com aqueles que efetuam esse trabalho". Se não há essa relação, os professores tutores não se reconhecem nem como professores, nem como mediadores do processo do qual estão imbuídos, isolando-se em atividades meramente burocráticas.

A normatização possibilitaria abranger, em conformidade com o processo de formação contínua do professor tutor, aspectos como:

a) a apresentação da disciplina e de suas atividades pelo professor pesquisador para seu grupo de professores tutores, o que propiciaria serem explicadas as ênfases, pontos críticos de aprendizagem e estratégias pedagógicas adotadas para a disciplina e seus conteúdos específicos;

b) a liberação e orientação prévia do material didático das disciplinas para que os professores tutores o apreciem antes de este ser disponibilizado para os estudantes;

c) a realização das atividades propostas primeiramente pelo professor tutor, para a busca de possíveis problemas de interpretação ou execução. Assim, caso houvesse dificuldades em compreender o tema ou conteúdo proposto, estas seriam encaminhadas ao professor da disciplina para esclarecimentos, em encontros presenciais;

d) o recebimento, pelo professor tutor, das dúvidas mais conceituais e específicas dos alunos nas disciplinas e a discussão com o professor da disciplina, sendo o professor tutor, nesse caso, o mediador entre as perguntas e as respostas.

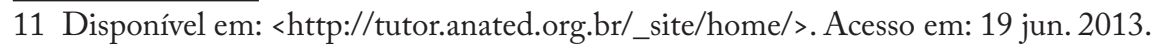


A normatização, assim, contemplaria as questões profissionais e pedagógicas em uma perspectiva coletiva e colaborativa com as relações vividas na tutoria.

\section{O DOMÍNIO CONCEITUAL NA EDUCAÇÃO PROFISSIONAL A DISTÂNCIA}

O segundo discurso coletivo (DSC2) apontou como ideia central os conhecimentos conceitual e pedagógico dos conteúdos curriculares de cada disciplina para o desempenho da mediação pedagógica.

\section{DSC2 - Conhecimentos conceitual e pedagógico dos conteúdos}

Eu não acredito muito nessa coisa que tu tenhas que ser da área para trabalhar, isso é, desde que tu sejas professor, tu estás atuando. Enquanto professor, a gente até tem condições de se apropriar dos conhecimentos, discutir, essa condição a gente tem, mas é fundamental a presença do professor, porque eu vou te dizer, eu sou de português e literatura e eu passei um pouquinho de trabalho, incomodei bastante os colegas na parte de matemática, porque matemática do ensino médio, quantos anos faz que eu não estudo e não vejo? Quando se tem essa aproximação, esse elo aí com o professor, facilita bastante, até porque nem sempre a gente vai ter colegas aqui, tutores, para orientar a gente na disciplina. A gente se socorre com os tutores mais experientes. Existiam alguns professores que deixavam a resposta e a gente às vezes corrigia algumas coisas e o professor resolvia que aquilo que a gente tinha corrigido tinha que dar certo e a gente tinha dado errado, interpretação. Nós somos três, quatro tutores para corrigir aquela atividade que não foi elaborada por nós, cada um vai analisar aquilo ali de uma maneira diferente, e ainda tem o agravante de pessoas que não são da área estarem ali corrigindo essas questões. Será que de repente, neste meio, a gente não estaria prejudicando alguns alunos, ou até ao contrário, beneficiando outros? Se não tivermos o contato com a pessoa, fica difícil. Ninguém é nota 10 em tudo. Ninguém vai gostar $100 \%$ de cada disciplina. Você tem aptidões para elas, tem motivações mais para uma disciplina ou para outra. A função do tutor seria estar no fórum de dúvidas respondendo e não a função do professor, mas para estarmos lá, nós teríamos que ter domínio do conteúdo. Eu acho que aqui no e-Tec o problema é maior do que na UAB, nós não temos gente da área para todas as disciplinas, nesse ponto nós estamos em desvantagem. Talvez o aluno veja o tutor como aquele que não sabe tanto.

O fato de não ser exigida, do professor tutor, a formação específica na área em que atuará se deve à característica das áreas de formação dos cursos da Rede e-Tec do IFSul CAVG. Podemos citar o exemplo do curso técnico em biocombustíveis, que não tem apresentado candidatos à tutoria habilitados nessa área específica de formação nos últimos processos seletivos.

Os professores tutores têm-se revelado qualificados pedagogicamente, pois possuem experiência no magistério; entretanto não apresentam, na maioria das vezes, o enfoque específico para o curso técnico a ser mediado. Trata-se de um grupo 
que, visivelmente, possui formação e qualificação pedagógica, mas reconhece suas fragilidades para o trabalho de mediação conteudista com os alunos.

A falta de domínio de conteúdo pelos professores nos processos de ensino e de aprendizagem é uma preocupação de longa data (Shulman, 1986). Shulman questiona: Como os professores transformam o conhecimento do conteúdo em algo que os alunos possam compreender? Como os professores empregam o conhecimento que têm do conteúdo para gerar explicações, representações ou esclarecimentos quando surgem dificuldades com o material didático ou alunos com dificuldades? Quais são suas fontes de analogias, metáforas, exemplos, demonstrações ou reformulações? Que preço pedagógico é pago quando a competência no assunto está comprometida pela não formação específica do professor tutor? Para o autor, "o simples conhecimento do conteúdo é passível de ser tão pedagogicamente inútil quanto a competência sem conteúdo" (idem, p. 8, tradução nossa).

A resolução n. 54, de 29 de outubro de 2009, ${ }^{12}$ excluiu o inciso III do artigo $6^{\circ}$ da resolução n. 36, de 13 de julho de 2009, ${ }^{13}$ o qual condicionava, para seleção dos professores tutores, o vínculo ativo no magistério da rede pública de ensino federal, estadual ou municipal. Essa mudança permite, atualmente, a contratação de docentes também da esfera privada, o que amplia a possibilidade de integrar sujeitos na equipe pedagógica com formação mais próxima da área dos cursos. Entretanto, a resolução exige um ano de experiência comprovada no magistério - exigência que busca contemplar o conhecimento pedagógico - mas que provavelmente não acarreta mudanças na área de conhecimento dos candidatos.

Shulman (2005, p. 21, tradução nossa) distingue, como conhecimento base para ensinar, "a capacidade de um docente para transformar seu conhecimento da matéria em formas que sejam didaticamente impactantes e ainda assim adaptáveis à variedade em que se encontram seus alunos quanto a habilidades e experiências".

É na relação com o professor pesquisador que o professor tutor encontra uma possibilidade de apropriar-se dos conteúdos para, então, mediá-los com os alunos. Assim, o professor tutor poderá desenvolver estratégicas pedagógicas para representar ideias complexas de uma determinada área do conhecimento, de forma que os estudantes as compreendam (Shulman, 2010).

Analisando o discurso coletivo, percebemos o conflito existente sobre as reais atribuições do professor tutor, pois, segundo eles, quando não há o convívio entre o professor tutor e o professor pesquisador, não se demarcam nem os domínios nem as competências de cada um. Quando existe a convivência, o professor tutor sabe que conta com alguém que é daquela área do conhecimento, com conhecimentos específico e pedagógico do conteúdo, e que pode contar com seu apoio para mediar. Nesse caso, por meio da convivência, os conteúdos já teriam sido trabalhados coletivamente entre professores tutores e professores pesquisadores. Ainda que

12 Disponível em: <http://www.fnde.gov.br/fnde/sala-de-imprensa/noticias/item/3363 \%AD-resolu\%C3\%A7\%C3\%A3o-cd-fnde-n\%C2\%BA-54-29-de-outubrode-2009>. Acesso em: 25 abr. 2013.

13 Disponível em: <http://www.fnde.gov.br/fnde/legislacao/resolucoes/item/3337>. Acesso em: 25 abr. 2013. 
um conteúdo específico estivesse fora de seu domínio conceitual, o professor tutor poderia mediá-lo, facilitando o seu acesso, muito mais do que propriamente tentar "ensiná-lo" ao aluno.

O professor tutor, em um trabalho colaborativo com o professor pesquisador, pode refletir pedagogicamente sobre o conteúdo para significá-lo ao mediá-lo com os alunos. Shulman (1996, p. 210, tradução nossa) ressalta que "colaboração é o casamento das insuficiências", por meio da qual difíceis desafios intelectuais, quase impossíveis de serem superados individualmente, tornam-se tangíveis se enfrentados coletivamente.

No modelo de ensino realizado pela Rede e-Tec do IFSul CAVG sempre existirá a possibilidade de um professor tutor não conseguir atender conceitualmente o aluno, pois, mesmo que tenha formação específica na área, não é contratado para ser professor tutor em uma disciplina, mas, sim, para ser professor tutor em um curso. $\mathrm{O}$ modelo permite essa fragilidade.

Para que os professores tutores pudessem ser contratados por disciplina, uma mudança política, pedagógica e curricular talvez fosse necessária, o que traria avanços, mas também outros desafios, como a troca frequente de professores tutores a cada disciplina, enfraquecendo os vínculos afetivos construídos durante o acompanhamento das turmas desde o início até o fim do curso. Entretanto, esse professor tutor a distância não pode ser aproveitado apenas para sanar aspectos técnicos, de acesso à informação e de inserção de trabalhos na plataforma. A competência do professor tutor é, para além do assessoramento dos alunos nas disciplinas, atuar como mediador pedagógico durante todo o curso.

O professor tutor deve ter conhecimento pedagógico da matéria para ser reconhecido efetivamente como mediador pelos alunos. Assim poderá orientar e desenvolver mais questionamentos do que respostas com seus aprendizes. Nesse sentido, Shulman (idem) aponta para um trabalho colaborativo, de forma que os professores pesquisadores sejam auxiliares das aprendizagens dos professores tutores, sugerindo textos e materiais complementares para suplementar seus conhecimentos específicos, gerando, assim, uma cultura de apoio na tutoria da educação profissional a distância.

\section{INTERAÇÃO NA TUTORIA DA EDUCAÇÃO PROFISSIONAL A DISTÂNCIA}

O terceiro discurso coletivo (DSC3) abordou o aspecto da falta de interação técnico-pedagógica entre os professores tutores e os professores pesquisadores e o seu impacto sobre o processo de mediação com os alunos.

\section{DSC3 - Interação técnico-pedagógica}

Eu tenho condições de estudar e de aprender, todos nós temos, mas a gente está fazendo isso sozinho, a gente não está tendo pares para essa discussão. Se a gente se fortalecer enquanto instituição, nesse vínculo, coordenação, professor, tutor, a gente vai chegar lá no aluno muito melhor. Raríssimos aqueles professores que vêm aqui falar alguma coisa, perguntar se está tudo tranquilo 
na disciplina. Seria muito melhor se essas horas que a gente tem aqui fossem realmente proveitosas para esse momento de discussão do curso com os professores. O professor é o responsável administrativamente pela disciplina, ele que vai responder por aquilo e ele tem uma conduta, nós temos que respeitar, nós somos um dos agentes daquele sistema, tem que ter essa interação, tem que ter um ajuste entre os dois, porque, senão, o cara fica ali perdido sem saber o que fazer. Seria muito produtivo se a gente tivesse encontros por curso, de tutores por curso, com os professores, e aí, esse tempo, a gente ficasse discutindo. Eu sinto toda a diferença quando o professor da disciplina vem aqui e fala com a gente, interage. A gente pode estar estabelecendo, nesta discussão prévia com o professor, articulação de disciplina, colocação no ambiente, ferramentas que vai usar, e nós vamos nos sentir mais valorizados. Enquanto a disciplina não acabar, ele tem que estar grudado nos tutores, aqui, que são o suporte dele. Se o professor não dá o apoio, é anti-humano o tutor conseguir responder aos alunos.

Observamos, no discurso coletivo, a ênfase quanto às questões pedagógicas percebidas na tutoria. Conforme Tardif e Lessard (2005, p. 249), a pedagogia escolar constitui-se em uma ação significativa, uma atividade comunicada que se dirige ao outro. Para os autores, a comunicação deve estar constantemente no centro da ação pedagógica. "Ela não é algo que vem somar-se à ação, mas é a própria ação como vivem os professores e os alunos" (idem, p. 253). Nesse sentido, esta se diferencia do conhecimento científico e técnico que se volta "para a objetivação e a manipulação dos fatos" (idem, p. 273).

Percebe-se o desejo dos professores tutores por espaços de convivência e interação com os professores pesquisadores, especialmente quanto às questões de conhecimento conceitual e pedagógico da matéria. Os reflexos dessa falta de interação, conforme apontado no discurso coletivo, impactam diretamente no processo de mediação com o aluno.

No modelo de educação profissional na modalidade a distância que temos vivenciado, o professor pesquisador geralmente desconhece as necessidades do aluno, pois não lida com ele da forma como faz o professor tutor. No ensino presencial temos a relação de um professor para "poucos" alunos; no ensino a distância da Rede e-Tec do IFSul CAVG temos uma relação de um professor para "muitos" alunos. É por essa razão que os professores tutores atuam na mediação. Seria difícil para o professor pesquisador, nesse modelo de ensino, atender e mediar um número grande de alunos de um determinado curso.

O conversar mostrou que as ações do professor pesquisador não se podem resumir ao planejamento, organização e postagem da disciplina no ambiente virtual. É necessário estar na convivência com o professor tutor enquanto a disciplina se desenvolve, pois, de outro modo, como o professor tutor poderá suprir a falta de domínio conceitual e pedagógico do conteúdo específico de uma determinada disciplina? Se o professor pesquisador, que possui o domínio conceitual, estiver com o ao professor tutor, haverá uma possibilidade para que este articule e (re)signifique o que aprendeu em sua convivência, com a probabilidade de um maior esclarecimento das dúvidas dos alunos. 
De acordo com a biologia do conhecer, "o ser vivo e sua circunstância se transformam de maneira congruente" (Maturana, 1990, p. 32). Segundo Maturana (idem), isso ocorre se estamos dispostos a conviver espontaneamente por certo tempo, transformamo-nos de maneira congruente, fazendo e refletindo sobre o fazer nesse espaço de convivência. A Figura 1 apresenta um exemplo de dois seres vivos (A e B) em interação, na congruência com suas circunstâncias $(\mathrm{C})$, em dois tempos distintos (t1 e t2) de suas existências.

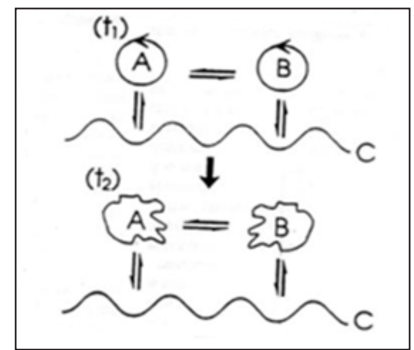

Figura 1 - Transformação na convivência. Fonte: Maturana (1990, p. 31).

Considerando a história de interações, percebemos, pela Figura 1, que os seres vivos e sua circunstância transformam-se de maneira congruente no fluir do viver. Assim, $\mathrm{A}+\mathrm{B}+\mathrm{C}$ em t1 transformam-se na convivência de maneira congruente durante sua história de interação para chegar à condição t2. Assim, o professor tutor transforma-se quando está na convivência com o professor pesquisador, e vice-versa, e transformam-se também os cursos, a forma de atuação na $\mathrm{EaD}$, ou seja, transformam-se também as circunstâncias. Para tanto, ambos devem configurar um espaço de convivência de tal modo que se possam aceitar mutuamente como legítimos.

Se não houver essa interação, o professor tutor ficará reproduzindo o que já está escrito nos materiais didáticos, estabelecendo-se aquele modelo antigo de educação a distância por correspondência, em que se recebia um material pronto e acabado, lia-se e respondia-se. O professor tutor não é um gravador que reproduz ao aluno os conceitos absorvidos do professor pesquisador. Ele é um professor: é de sua natureza a consciência de compreender para ensinar.

De acordo com Gonzalez (2005), o professor tutor deve ter a capacidade de mediar os conhecimentos; entretanto, esses conhecimentos não se constroem somente sobre seu olhar acerca do conteúdo. Cabe ao professor tutor apropriar-se dos conteúdos propostos no material das aulas, para que possam ser articulados e expandidos durante suas interações presenciais e virtuais com os professores de cada disciplina.

A interação virtual pode ser realizada por meio de fóruns de discussão de acesso específico aos professores, potencializando a troca e a mediação dos saberes específicos de cada disciplina. Rodrigues $(2007$, p. 34) defende a hipótese de que:

redes conversacionais virtuais que permitam a convivência, a interligação dos saberes e as trocas de experiências podem ser um caminho na direção de uma 
formação sustentada pela cooperação, possibilitando aos sujeitos um espaço para discussões, interações e comunicações de forma reflexiva.

A apropriação dos conhecimentos específicos, por parte dos professores tutores, tende a acontecer na convivência se houver o processo de interação em encontros recorrentes com o professor pesquisador. Maturana (1999, p. 151) aponta que educar é conviver; para o autor, transformações educativas acontecem quando se adota a postura de configurar espaços de convivência, nos quais educadores e educandos possam se aceitar mutuamente como legítimos na convivência.

\section{CULTURA E FORMAÇÃO NA TUTORIA DA EDUCAÇÃO PROFISSIONAL A DISTÂNCIA}

O quarto discurso coletivo (DSC4) abordou a cultura e a formação docente na EaD profissionalizante.

\section{DSC4 - Cultura e formação na EaD}

Nós todos aqui fomos concebidos através de uma educação clássica, tentando fazer uma coisa inovadora sem ter um preparo ou uma estratégia de ação inovadora. Até com medo de não querer errar, a gente acaba fazendo algumas coisas meio parecidas com o que se faz normalmente. Deveria se usar uma estratégia diferente, deveríamos usar outras armas. A gente está numa instituição pública, ainda por cima, vindo de uma escola que era técnico-agrícola, uma coisa bem clássica. Essa concepção de inovação, de usar mídias, de usar essas ferramentas mais tecnológicas não está no dia a dia do entendimento. Não é uma questão de não gostar, de não querer, é uma inércia que tem que se quebrar. O professor também vai poder se apropriar disso para dentro das aulas clássicas dele, como ferramenta de suporte. Eu acho que tem muitos professores que não estão preparados, não têm experiência, fica uma coisa muito fria. $\mathrm{Na}$ grande maioria, é apostila e exercícios. A questão da humanização no ambiente é uma coisa superimportante. É um cuidado pedagógico com quem está do outro lado. Eu não gosto desses ambientes duros, a mim me incomoda. $\mathrm{Na}$ realidade, o que acontece: os professores estão acostumados com a educação presencial, não estão acostumados com a educação a distância, eles querem fazer uma aula expositiva no ambiente virtual, isso é, a apostila passada no presencial como se fosse a mesma modalidade de ensino. Ainda existe essa coisa de que no presencial têm que ir, mas no a distância não, ainda tem essa cultura. $\mathrm{O}$ pessoal tem que se dar conta que aqui também tem que dar conta daquela disciplina e daquele aluno que tá lá no computador. É o comprometimento que o professor tem no presencial que tem que ter no a distância. Não sei se é a cultura da escola, a cultura do próprio professor, que não era a distância. Professor preparado para mexer com as mídias é importante. Os professores não estão acostumados e 
isso prejudica muito, pois torna o ambiente enfadonho. Uma das saídas são as videoaulas à disposição em qualquer horário. Acho que a webconferência faz com que o aluno participe com mais dedicação e acho importantíssima a questão do fórum de tutores. O show também faz parte do pacote e o nosso show está muito monólogo.

O discurso coletivo traz indícios significativos de que os professores tutores reconhecem as limitações dos processos de ensinar e de aprender a distância impostas pela cultura do ensino presencial; ou seja, aplica-se no modelo a distância o que se conhece do modelo presencial.

Como professores, temos uma cultura que nos constitui e nos modela, fazendo com que sejamos o professor que aprendemos a ser com nossos professores. Desde cedo aprendemos como atua um professor: um sujeito que fala para que $\mathrm{o}(\mathrm{s})$ outro(s) escute(m). Esse modelo foi incorporado pelos saberes da experiência. Está na ontogenia do nosso ser, presente no dia a dia de nossas escolas. São valores, hábitos, práticas, reflexos culturais pedagógicos vividos desde a fase pré-escolar. Essa cultura perpetua-se e é muito intensa em nossa vida; está no viver da humanidade. Segundo Maturana (2002, p. 117):

o viver humano constitui e se constitui recursivamente no viver psíquico, mental e espiritual e, portanto, surge no conviver como um processo no qual se aprende espontaneamente, e sem esforço algum, o espaço psíquico, mental e espiritual da cultura a que se pertence.

$\mathrm{O}$ modelo de EaD apoiado em tecnologias digitais, com possibilidade permanente de interação, é um modelo recente, que está ainda em construção. Vivemos em um modelo de ensino imposto pela cultura presencial, no qual trabalhamos, enquanto professores, na maior parte do tempo isolados ou, quando muito, temos um bolsista ou monitor para nos ajudar a resolver um exercício ou aula prática. Não estamos acostumados com alguém que nos ajude a mediar pedagogicamente um conteúdo específico. Não nos constituímos na cultura do "mediador a distância”, imbricada pelas tecnologias digitais, compreendida como cibercultura. ${ }^{14}$ Para Lévy (1993, p. 117), "é mesmo possível que não nos apercebamos da existência de novos estilos de saber, simplesmente porque eles não correspondem aos critérios e definições que nos constituíram e que herdamos da tradição".

É preciso romper com as práticas do ensino presencial quando, nele constituídos, ainda acreditamos que se trata de um modelo eficaz? Segundo Tardif (2005, p. 285), "a ausência de uma base de conhecimentos socialmente reconhecida leva os professores a privilegiarem seus próprios conhecimentos do trabalho". Parece que os professores não estão acostumados com uma proposta de mediação colaborativa. Para Thurler (2002, p. 105), quando existe a colaboração profissional entre os pro-

14 Cibercultura é um neologismo que especifica o conjunto de técnicas (materiais e intelectuais) de práticas, atitudes, modos de pensamento e valores que se desenvolvem com o crescimento do ciberespaço (Lévy, 1999, p. 16-17). 
fessores, forma-se uma cultura que representa "a antítese do individualismo e do cada um por si”, contribuindo para o êxito das ações pedagógicas e possibilitando uma formação contínua entre os professores. Entretanto, segundo a autora, não há receitas simples para instaurá-la.

Os professores tutores apontam no discurso coletivo que os professores pesquisadores não entendem seu papel pedagógico no ambiente de tutoria, mas, sim, apenas o papel burocrático. Assim, não se constitui uma relação de colaboração entre eles, nem a expectativa de uma mediação significativa.

O professor pesquisador, ao entender quem é o professor tutor, acredita em seu potencial e lhe dá importância no processo pedagógico, valorizando seus conhecimentos, seu trabalho e o quanto ele pode ajudar no processo de ensinar e de aprender. Esse movimento retroalimenta o conhecimento do professor pesquisador. Para Shulman (1996), uma cultura de apoio gera uma interdependência entre seus membros, construída pela atividade, reflexão e colaboração. $\mathrm{O}$ autor ressalta que "aprender a partir da experiência é quase impossível sem o apoio de outros, as suas visões alternativas, suas perspectivas complementares, seus papéis como ouvintes ativos e amigos críticos" (idem, p. 214, tradução nossa).

Pelo discurso, percebemos que não há na tutoria essa cultura de relação, de interação entre os professores pesquisadores e os professores tutores, que poderia abranger a própria mediação pedagógica no sentido do acompanhamento conteudista. Para Rodrigues (2007, p. 35), "construir uma rede de conversação, na qual os sujeitos estejam comprometidos com sua própria formação e a de seus parceiros, parece ser um dos desafios lançados à educação e, consequentemente, às instâncias de formação de professores".

Segundo Lévy (1998, p. 31), “a inteligência coletiva só tem início com a cultura e cresce com ela”. Para o autor, em um coletivo inteligente, um conjunto de pessoas trabalha colaborativamente assumindo como objetivo a negociação permanente do papel de cada um, aprendendo a se conhecer para pensar junto como comunidade.

Um processo de formação na tutoria da Rede e-Tec do IFSul CAVG, estabelecido na recursividade do conversar entre professores pesquisadores e professores tutores, tem como propósito mobilizar discussões relacionadas aos conhecimentos específicos de cada disciplina, em direção a um coletivo inteligente para atuar na mediação pedagógica com significado e autonomia, favorecendo uma cultura colaborativa nas relações vividas na tutoria da educação profissional a distância.

\section{ALGUMAS REFLEXÕES FINAIS}

Com os cursos a distância da Rede e-Tec, uma nova cultura começa a configurar-se na educação profissionalizante do IFSul CAVG. Professores, tutores e alunos assumem o desafio de ensinar e aprender nessa modalidade de ensino permeada por tecnologias digitais, em que os cursos técnicos são (re)configurados para o ambiente virtual, as disciplinas são planejadas e organizadas pelos professores pesquisadores e a mediação pedagógica é atribuída aos professores tutores.

Porém, de que forma os processos de mediação pedagógica vão se cristalizando nessa modalidade de ensino? Os professores tutores devem lidar essencialmente com 
questões administrativas ou mediar efetivamente os conteúdos durante o processo de ensino e aprendizagem? As interações do professor pesquisador devem ser realizadas com os professores tutores ou com os alunos, afinal de contas?

Os discursos coletivos expressam que os professores tutores têm demonstrado descontentamento com a separação de tarefas. Uma maior aproximação com os professores pesquisadores viabilizaria um trabalho coletivo e colaborativo, permitindo que os professores tutores (re)significassem seus conhecimentos na convivência.

As relações de apoio e colaboração somente acontecerão se forem garantidos espaços de reflexão para que os professores tutores possam ser aceitos como legítimos na convivência. Enquanto não rompermos com esse modelo disjuntivo, não teremos um processo de formação ou uma cultura de educação profissional a distância na qual o professor tutor sinta-se parte no processo, operando colaborativamente com o professor pesquisador e com os alunos. Como os professores tutores não são os professores autores das disciplinas, precisam de autonomia para ir buscar aquilo que lhes falta. Mas como saberão o que é significativo ou não em determinada disciplina se não conviverem com os professores pesquisadores?

O estudo mostrou a necessidade de uma reconfiguração do espaço de interação e de reflexão da tutoria, a ser permeada por redes de conversação técnico- pedagógicas entre professores tutores e professores pesquisadores para o tratamento dos conteúdos específicos das disciplinas dos cursos técnicos, em um processo de formação contínua. Os professores pesquisadores, na convivência com os professores tutores, poderiam conhecer suas realidades, seus conhecimentos prévios, competências e habilidades, para trabalharem os conteúdos específicos de forma que os professores tutores pudessem (re)significá-los pedagogicamente com os alunos.

A formação teórica e prática dos professores tutores poderá ser uma ação que vise potencializar a mediação pedagógica a distância na educação profissional. Acreditamos que uma formação ministrada pelos próprios professores das disciplinas, em momentos presenciais e virtuais, motivará os professores tutores a despender esforços em estudos relativos aos conteúdos técnicos e específicos de cada disciplina, possibilitando, por conta de suas apropriações no processo, mediar pedagogicamente, com os alunos, os conhecimentos adquiridos, com mais segurança e autonomia.

Uma proposta de formação para o professor tutor, conduzida pelo professor pesquisador e permeada pelo uso das tecnologias digitais, pode contribuir para o desenvolvimento do saber e das competências necessárias para mediar pedagogicamente os conteúdos curriculares. O estudo também propõe um conversar que aproxima, incentiva, transforma e humaniza o processo de mediação pedagógica para além das formas habituais da cultura docente presencial.

Assim, por meio de um conversar técnico-pedagógico e da troca de experiências entre os professores pesquisadores e os professores tutores, a formação contínua configura-se na perspectiva de um coletivo inteligente, vivida presencialmente por meio desse conversar e potencializada virtualmente pelas interações síncronas e assíncronas realizadas por meio do AVA. Nesse processo de formação, os conceitos teóricos e científicos que fazem parte dos conteúdos curriculares de cada disciplina são articulados com sua aplicação prática no mundo do trabalho. Com essa formação, os professores tutores poderão sentir-se mais preparados e capazes de produzir sentido, significando, na prática, seu processo de mediação pedagógica. 
A normatização pode ser o caminho para efetivar uma rede de conversação colaborativa entre professores tutores e professores pesquisadores como proposta de formação contínua. Trata-se de uma normatização na perspectiva de uma formação técnico-pedagógica que aponte para a (re)configuração do espaço de convivência da tutoria, de tal forma que as redes de conversação sejam constituídas de saberes específico e pedagógico dos conteúdos curriculares. Por fim, desejamos que esses espaços possam transformar a mediação pedagógica dos professores tutores em um caminho científico, de atitudes e valores associados a posturas colaborativas, investigativas e críticas, em vez de condutas isoladas, centradas no conhecimento prático do senso comum, sucedidas, muitas vezes, de experiências vividas no ensino presencial.

\section{REFERÊNCIAS}

Gonzalez, M. Fundamentos da tutoria em educą̧ão a distância. São Paulo: Avercamp, 2005.

Gutierrez, F.; Prieto, D. A mediação pedagógica: educação a distância alternativa. Campinas: Papirus, 1994.

LefÈvre, F.; LefÈvre, A. M. O discurso do sujeito coletivo: um novo enfoque em pesquisa qualitativa (desdobramentos). Caxias do Sul: EDUCS, 2005.

LÉVY, P. As tecnologias da inteligência: o futuro do pensamento na era da informática. Rio de Janeiro: Editora 34, 1993. 1998.

.A inteligência coletiva: por uma antropologia do ciberespaço. São Paulo: Loyola, Cibercultura. São Paulo: Editora 34, 1999.

Masetto, M. T. Mediação pedagógica e o uso da tecnologia. In: Moran, J. M.; Masetto, M. T.; Behrens, M. A. Novas tecnologias e mediação pedagógica. São Paulo: Editora 19, 2012.p. 133-173.

Maturana, H. Uma nova concepção de aprendizagem. Dois Pontos, Belo Horizonte: SEER, v. 2, n. 15, p. 28-35, 1990.

. Transformación en la convivencia. Santiago do Chile: Dolmen Ediciones, 1999. Cognição, ciência e vida cotidiana. Belo Horizonte: Editora UFMG, 2001. A ontologia da realidade. Belo Horizonte: Editora UFMG, 2002.

2009. . Emoçôes e linguagem na educaşão e na política. Belo Horizonte: Editora UFMG,

Moore, M.; Kearsley, G. Educação a distância: uma visão integrada. São Paulo: Cengage Learning, 2008.

Pereira, A. Ambientes virtuais de aprendizagem: em diferentes contextos. Rio de Janeiro: Ciência Moderna, 2007.

RodRIGUEs, S. Rede de conversaşão virtual: engendramento coletivo singular na formação de professores. 2007. Tese (Doutorado em Informática na Educação) - Universidade Federal do Rio Grande do Sul, Porto Alegre, 2007. 
Shulman, L. Those who understand: knowledge growth in teaching. Educational Researcher, Washington: American Educational Research Association, v. 15, n. 2, p. 4-14, 1986.

Just in case: reflections on learning from experience. In: Colbert, J.; TRImble, K.; Desberg, P. (Eds.). The case for education. Contemporary approaches for using case methods. Needham Height: Allyn Bacon, 1996. p. 197-217.

Conocimiento y enseñanza: fundamentos de la nueva reforma. Profesorado. Revista de Currículum y Formación del Profesorado, Granada: AUFOP, v. 9, n. 2, 2005.

Lee Shulman: "o Aprendizagem Baseada em Problemas (ABP) requer que os estudantes assumam os riscos de expor suas opiniões e ideias”. Entrevista de Daniela Ingui. 2010. Divulgación y Cultura Científica Iberoamericana. Disponível em: <http:// www.oei.es/divulgacioncientifica/entrevistas_071.htm>. Acesso em: 14 ago. 2013.

TARdif, M. Saberes docentes e formação profissional. Petrópolis: Vozes, 2012.

.; Lessard, C. O trabalho docente: elementos para uma teoria da docência como profissão de interações humanas. Petrópolis: Vozes, 2005.

Thurler, M. G. O desenvolvimento profissional dos professores. In: Perrenoud, P. As competências para ensinar no século XXI: a formação dos professores e o desafio da avaliação. Porto Alegre: Artmed, 2002. p. 89-111.

\section{SOBRE OS AUTORES}

Fernando Augusto Treptow Brod é doutor em educação em ciências pela Universidade Federal do Rio Grande (FURG). Professor do Instituto Federal Sul-rio-grandense (IFSul).

E-mail: ftbrod@gmail.com

Sheyla Costa Rodrigues é doutora em informática na educação pela Universidade Federal do Rio Grande do Sul (UFRGS). É professora da Universidade Federal do Rio Grande (FURG).

E-mail: sheylacrodrigues@gmail.com

Recebido em abril de 2014

Aprovado em março de 2015 